\title{
Learning Potential in Mathematics through Imagination and Manipulation of Building Blocks
}

\author{
Concetta Pirrone \\ University of Catania, Via Biblioteca, 4, Catania 95124 \\ concetta.pirrone@unict.it \\ Antonio Nicolosi \\ University of Catania, Via Biblioteca, 4, Catania 95124 \\ antonio78@gmail.com \\ Alessia Passanisi \\ Kore University, Cittadella Universitaria - Enna 94100 \\ alessia.passanisi@unikore.it \\ Santo Di Nuovo \\ University of Catania, Via Biblioteca, 4, Catania 95124 \\ s.dinuovo@unict.it
}

Doi:10.5901/mjss.2015.v6n4s3p152

\begin{abstract}
In line with scientific literature, there is a growing interest in building-block play. In fact, through this kind of play, children acquire both the abilities for abstract thought and symbolic representation and an understanding of rules-all of which are fundamental for mathematical understanding. This study explores the relationship between constructive play, mathematical skills, and mental imagery in children aged 10 to 12 years through the applications of three kinds of test: LEGOB block play, objective mathematical tests for primary school, and mental imagery tests (MITs). Gender did not significantly affect the tests' outcomes with the exception of the MIT visuo-spatial memory subtest, on which males reported better scores. Mental imagery correlated positively and significantly with all the variables involved in this study. Moreover, mental imagery was shown to have a mediating role in the relation between block play and mathematics. The results of this study may be useful for developing teaching and learning techniques based on construction play.
\end{abstract}

Keywords: LEGO block play, mathematical skills, mental imagery

\section{Introduction}

In recent years, the scientific literature has revealed an increasing interest in the "learning potential" underlying buildingblock play, as there is a widespread belief among psychologists and educators that playing has a very important role in the development of adaptive personality traits (e.g., Schimmenti et al. 2015; Pace et al., 2015). Moreover, this type of play can be considered as a medium through which children develop cognitive skills (Pepler \& Ross, 1981). Most of these studies have focused on the relationship between building-block play and mathematics, trying to understanding what mechanisms allow the transformation of LEGO-play skills into calculation skills. In the scientific literature, the relationship between play, mathematics, and visuo-spatial skills has been widely explored (Tracy, 1987; Brosnan, 1998; Caldera et al., 1999; Hegarty \& Kozhevnikov 1999; Casey et al., 2008; Casey, Pezaris, \& Bassi, 2012; Oostermeijer, 2014; Nath, 2014), emphasising the role that mental imagery may play in this relationship. Mental imagery has been investigated in connection with both mathematics and games, but the mediating role that mental imagery plays between building-block play and mathematics, which may be more relevant, has rarely been considered. In this study, we analysed the relationship between building-block play and mathematical skills by testing whether mental imagery mediates this relationship. 


\subsection{Why Playing with LEGO Improves Mathematical Skills?}

Building-block play provides opportunities to integrate various types of learning in multiple areas of development. According to Verdine (2014), playing with blocks may be crucial in helping pre-schoolers to develop "spatial thinking"envisioning where blocks go in relation to each other as they build. Deciding whether a block goes over or under another block, or whether it is aligned or perpendicular to it, are just the kinds of skills that support later learning in science, technology, engineering, and math (STEM). When children manipulate and assemble pieces, building-block play furnishes opportunities to learn and practice visual perception along with gross and fine motor skills. As children handle blocks, they become mentally active, learning to interpret and process sensory information. As proposed by Vygotsky (1976) and more recently by Pickett (1998), building-block play may support academic skills; for instance, the representational aspects of blocks stimulate symbol production (Stroud, 1995). Piaget (1945) and Reifel (1984) explained the main role that blocks play as children begin to internalise the physical foundation of all mathematical and scientific concepts. By physically manipulating blocks, young children learn the meaning of size, shape, length, weight, capacity, and balance. Even before they can label or describe blocks, children have internalised the blocks' physical attributes and established an important relationship between the objects. In doing so, they increase and stimulate problem-solving skills, logical thinking, and conceptual understanding according to the specific context (Hampton et al., 2011).

According to Sarama and Clements (2009), the children's everyday experience forms an intuitive, implicit conceptual foundation for mathematics. Later, children represent and elaborate on these ideas, creating models of everyday activity with mathematical objects, such as numbers and shapes; engaging in mathematical actions, such as counting or transforming shapes; and using mathematics to build structures. Sarama and Clements call this process "mathematization" (p. 316). Construction tasks, such as object assembly, are paradigmatic examples of complex events (Zacks \& Tversky, 2003) that depend upon visual search and spatial problem-solving, including visualisation through mental imagery, which are the foundation of math skills.

\subsection{The Importance of Imagination in Learning Mathematics}

Psychological studies on procedures for teaching and learning in mathematics have focused on the effectiveness of imagination. As stated by Jencks (1972), learning new concepts usually begins as the child's senses progress. They form mental images of what they perceive with those senses. These images provide the foundation for insight. When the child receives first-hand experiences that help him or her to build the necessary images, learning becomes deeper and more penetrating (Pellerone et al. 2015; Passanisi \& Di Nuovo, 2015). It follows that a large part of understanding consists of constructing representations of various types. These representations are often both external (e.g., a picture) and mental (e.g., a feeling), such as the geometric image of complex numbers forming the complex plane or the kinetic model for elementary calculus (Arnoux, 2009). The first specific study on the relationship between imagination and mathematics dates back to Bishop $(1973,1989)$, who studied the crucial relationship between spatial ability and visualisation. Brown and Wheatley $(1990)$ and Presmeg $(1986,1992)$ investigated the role of visually mediated processes in high school mathematics, in which individual students' thinking was probed in clinical interviews. The authors indicated that students use imagery in the construction of mathematical meaning, thus affirming that learning frequently involves the use of imagery and that it must include very abstract and vague forms of imagery. Dawe and Anderson (1993) showed that the use of visualisation strategies in teaching mathematics is related to higher student performance in mathematics; he also found that integrating holistic and analytical approaches leads to even better results. Mason (1992) suggested that the images can be viewed as either eidetic, following the exposure to a visual object, or constructed from other images; he asserted that it is not just the creation of mental image but the use of that image as a mental "screen" in visual thinking that constitutes mathematical learning. Furthermore, Hegarty and Kozhevnikov (1999), after running a study on the relationship between imagination and visuo-spatial problem-solving in mathematics with 12-year-old children, defined two types of visualizers: schematic types, who are generally successful in mathematical problem solving, and pictorial types, who are less successful than schematic types. Despite this, the usefulness of building representations is often downplayed as an aside or ignored entirely. Two possible explanations are that good representation is not easy to obtain and that many teachers and researchers underestimate the importance of the classroom environment (Arnoux, 2009). However, this type of implicit stimulation activity, especially in kindergarten and the early elementary grades, was highlighted by Varol and Farran (2006); Klibanoff, Levine, Huttenlocher, Vasilyeva, and Hedges (2006); and Clements and Sarama (2007), who stressed the importance of internal and external sound environments and the importance of activities with concrete materials, such as building-block games. 


\subsection{The Link Between building Block Play, Mental Imagery, and Mathematics}

Playing with building blocks requires the ability to create a mental model of the completed objects or, at least, intermediate images to be updated during construction. Since the reproduced item often is not physically present in the child's perception (e.g., models of helicopters, bulldozers, or cranes), mental imagery serves as a guide to create the target object. Block games stimulate and strengthen children's ability to intervene in reality by manipulating and using their imagination; the child learns to think in terms of planning and to develop a creative approach. This synthesises the non-existent object and the rules of external reality, which now appear malleable within certain limits:

"Block construction also offers an opportunity for wonder and exploration. What happens when we put the big block on top of the smaller one-will it balance or will it fall down? Can I make a bridge? A tower? How tall can I build them before they teeter over? Young children can investigate possible worlds as they build block constructions". (Shaklee et al., 2008, p. 4)

This form of constructive play involves almost all of the same manipulative skills utilised in the acquisition of basic math skills (e.g., rotations, assemblies, spin-offs, shape analysis, spatial relationships, measurements, quantities, and relations between parts) in a continuous reference between imaginative internal reality and concrete external reality. This process allows children to create a sort of communication "channel" between the internal and external worlds. This channel is the same means used to transmit culture and produce knowledge. Thus, the products of the block games may, with good reason, be thought of as imaginary structures that reproduce real objects (Hirsch, 1996; Lunzer, 1955; Reifel, 1996).

\section{Objectives of the Present Study}

While scientific literature reports positive relationships between children's constructive play activities and math, and between building-block play and mental imagery, a relationship between constructive play, mathematical skills, and mental imagery has been poorly investigated (Pirrone \& Di Nuovo, 2014). In fact, the majority of research has emphasised the relationship between building-block play, math, and visuo-spatial skills, completely neglecting the crucial mediating role that mental imagery can play in facilitating the application of building-block play skills to the early acquisition of basic math skills. Thus, there are compelling reasons to better explore this link. Taking into account a possible difference between boys and girls, the main aim of this study was to test the possible mediating role played by mental imagery in predicting good mathematical performances; we also explored the possible influence of other variables (e.g., visuo-spatial memory and visual perceptual skills) on the prediction of mathematical performances.

\section{Method}

\subsection{Participants}

The sample consisted of 42 children ( 25 males and 17 females) in the fifth grade. The average age was 10.45 years (range: 10-11; standard deviation: 0.5). None of the participants included in the sample had intellectual or learning disabilities or other deficits. The sample was recruited from two schools; the schools were similar with regard to socioeconomic level and location.

\subsection{Measures}

Objective mathematical tests for primary school (Soresi et al. 1992). This test suitable for children between 6 and 11 years evaluates arithmetic and calculation skills through the following indices: Logic, Arithmetic, Geometry and Measurement, Statistics-Probability-Information, Problems. Each of the subtests has a score, whose sum gives the total score of the test. The reliability, both for each subtest and for the whole test, has been evaluated by the authors by means of test-retest correlation, Guttman test and inner consistency (Cronbach's alpha). For the total scores of the 5/B test, the one used in this research, the correspondent coefficients are 0.89 (test-retest), 0.90 (Guttman) and 0.96 (Cronbach).

MIT Mental imagery tests (Di Nuovo et al. 2014). These tests are derived, with adaptations, from Brandimonte, Hitch, \& Bishop (1992), Brooks (1968), Kosslyn, Margolis, Goldknopf, Daly, and Barrett (1990), and Riddoch (1990). This 
test is organized in two parts; the first includes specific tests of mental imagery with low request of memory skills and perception. The second part, includes attention span test, memory and visual-spatial perception test.

Including test used in the first part:

Visualising letters. The subject is requested, without seeing the stimuli and using only his/her imagination, to say which lower-case letters have parts extending above or below the central body (e.g., a, f, u, or p) and which upper-case letters have curved parts (e.g., A, P, G, or R).

Brooks' Test. Using his/her imagination, the subject is asked to walk along the contour of a large upper-case letter $F$ printed on a card that the child had viewed for 30 seconds. The subject should say whether the edges encountered when moving from the lower left corner (indicated with an arrow in the card previously seen) in a counter-clockwise direction, are external or internal.

Clock. The task requires imagining a clock with hands indicating 10 past 10, imagining the clock reflected in a mirror and saying what time will be shown on the reflected clock after ten minutes.

Cube. A large cube is shown for 30 seconds; it is composed of nine small cubes per face $(3 \times 3)$, and the external faces are colored. After the figure is removed, the subject is asked to state how many small cubes have three external (visible and colored) faces, how many have two, and how many have one or none.

Subtraction of parts. A digital display showing the number 88 (i.e., all the segments composing the display are illuminated) is shown for 10 seconds. Then, another digital display with selected segments of a two-digit number illuminated is shown for 10 seconds. This figure is removed, and the subject is asked to imagine what two-digit number will remain after subtracting the parts of the new figure from the figure with the number 88 observed previously.

Mental exploration of a map. A simple map representing a small island is shown for a minute; on the map, there are a small forest, a house, a church and a lake; once the map is removed, the subject is asked questions about the position and relative distance among these figures on the island

Imagined paths. The subject is asked to imagine a small ball and to move it mentally following the sequences proposed by the researcher; he/she is then asked to tell whether the ball is in a higher, lower or at the same level at the end of the path than at its beginning

Mental representation of shapes. The researcher names come objects from a list, and the subject is asked to tell if they may have a "higher" or "larger" shape.

Including test used in the second part:

Forward and backward digit span. Participants are presented with a series of digits (e.g., '8, 2, 4') and must immediately repeat them back. If they do this successfully, they are given a longer list (e.g., '9, 2, 4, 1'). The length of the longest list a person can remember is that person's digit span. While the participant is asked to enter the digits in the given order in the forward digit-span task, in the backward digit-span task the participant needs to reverse the order of the numbers.

Object memory and objects' position memory. Seven objects are first presented for 30 seconds; the subject is then asked to recall them; afterwards 6 objects are presented in a checkboard for 30 seconds and the subject is then asked to recall the objects as well as their position in the checkboard.

Checkboard test (visuo-spatial memory). the researcher shows, in succession, 6 checkboards with some colored squares, each one for 10 seconds, asking afterwards the subject to reproduce the position of the colored squares.

Visuo-perceptual tests (specular spatial position, step 1 and 2): the subject is asked to perform a specular reproduction of some figures, with the aid of a matrix of dots.

A total test score may be obtained by summing up the scores for each subtest. The psychometric properties of the total score were assessed in previous validation studies (Di Nuovo, 2013) and found good reliability (alpha=0.81).

LEGO® block play: the smartphone application LEGO® Life of George (see http://george.lego.com/it-it/) proposes stylized models of real objects, with progressively increasing difficulty, which must be reproduced by the subject using the bricks included in the package; once the model has been proposed, the program starts an increasing time counter, stopping as soon as the subject completes the brick reproduction and puts it on a grid (included in the package) taking a photo with the smartphone. After comparing the reproduction and the model, the program assigns a global score. If the subject does not complete and photograph the reproduction before the time counter expires, the program automatically sets a zero score. The output data are the elapsed time (up to the photo) and the global score. Because these variables are strongly and significantly correlated ( $\rho s=-0.812, p<0.01$ ), only the global score has been assumed as a general indicator of performance. 


\section{Results}

A preliminary analysis compared performances by gender, which did not significantly affect the tests outcome. This is true for the global scores of the mathematical $(z=-1.33, p=0.182)$ and mental imagery tests $(z=-0.552, p=0.581)$, for building block play $(z=-0.205, p=0.838)$ and the three memory subtests: digit span $(z=-0.09, p=0.92)$, objects memory $(z=-0.01, p=0.98)$ visuo-spatial memory $(z=-2.850, p=0.004)$, only the latter exhibited a different trend, as males displayed significantly better performances than females. No significant difference was found for the visuoperceptual tests: subtest $1(z=-0.643, p=0.520)$, subtest $2(z=-0.016, p=0.988)$. Considering the substantial lack of influence of gender, further analyses were conducted with no gender distinction.

A Spearman linear correlation analysis was performed to test the relationship between the different variables considered in this study (see fig. 1). The single linear correlations were significant between mathematics and mental imagery ( $\rho s=0.555, p<0.01$ ), between mathematics and block play $(\rho s=0.353, p<0.05$ ) and between block play and mental imagery ( $\rho s=0.390, p<0.01$ ). As for memory and visuo-perceptual tests, only mental imagery was significantly correlated with all the variables: objects memory ( $\rho s=0.316, p<0.05$ ), visual spatial memory ( $\rho s=0.430, p<0.01$ ), digit span memory ( $\rho s=0.315, p<0.05$ ); specular reproduction 1 ( $\rho s=0.47, p<0.01$ ), specular reproduction 2 ( $\rho s=0.36, p<$ 0.01 ). Building block play and mathematics did not significantly correlate with any variable. Data showed significant correlations of mental imagery with all the variables involved in this study; this is why we decided to test the hypothesis that mental imagery plays either a total or a partial mediation role in the relation between block play and mathematics. Simple and multiple regression analyses (see fig. 2) showed that Baron and Kenny's conditions were fulfilled (Baron and Kenny 1986): a) the independent variable (block play) significantly predicted the mediator (mental imagery) ( $B=0.385, p<$ $0.05) ; b)$ the mediator significantly predicted the dependent variable (mathematical abilities), when the regression analysis also included the independent variable $(B=0.505, p<0.01) ; c)$ the regression coefficient was significant if the mediator was not included in the analysis $(B=0.351, p<0.05)$, but it was not if the regression analysis also included the mediator ( $(=0.156$, n.s.). The Sobel test (Baron e Kenny 1986) confirmed the significance of the mediation effect $(t=$ $2.207, p<0.05)$.

Finally, a multiple regression analysis, including all the variables (see fig. 3), with mathematics as the independent variable, confirmed a prediction effect by only mental imagery $(B=0.501, p<0.01)$.

Figure 1 - Spearman correlations matrix, all variables $\left({ }^{*} p<0.05,{ }^{* *} p<0.01\right)$

\begin{tabular}{|l|c|c|c|c|c|c|c|c|}
\hline Linear Correlations & $\begin{array}{c}\text { Mathematical } \\
\text { abilities }\end{array}$ & $\begin{array}{c}\text { Mental } \\
\text { imagery }\end{array}$ & $\begin{array}{c}\text { LEGO } \\
\text { block play }\end{array}$ & $\begin{array}{c}\text { Digit span } \\
\text { memory }\end{array}$ & $\begin{array}{c}\text { Visual spatial } \\
\text { memory }\end{array}$ & $\begin{array}{c}\text { Objects } \\
\text { memory }\end{array}$ & $\begin{array}{c}\text { Specular } \\
\text { reproduction 1 }\end{array}$ & $\begin{array}{c}\text { Specular } \\
\text { reproduction 2 }\end{array}$ \\
\hline Mathematical abilities & $I$ & $0,555^{* *}$ & $0,353^{*}$ & 0,182 & 0,055 & 0,214 & 0,233 & $0,454^{* *}$ \\
\hline Mental imagery & $0,555^{* *}$ & $I$ & $0,390^{*}$ & $0,315^{*}$ & $0,430^{* *}$ & $0,316^{*}$ & $0,471^{* *}$ & $0,367^{*}$ \\
\hline LEGO block play & $0,353^{*}$ & $0,390^{*}$ & $I$ & 0,032 & 0,246 & 0,198 & 0,160 & 0,294 \\
\hline Digit span memory & 0,182 & $0,315^{*}$ & 0,032 & $I$ & $0,381^{*}$ & 0,143 & 0,297 & 0,294 \\
\hline Visual spatial memory & 0,055 & $0,430^{* *}$ & 0,246 & $0,381^{*}$ & $I$ & 0,090 & 0,160 & 0,133 \\
\hline Objects memory & 0,214 & $0,316^{*}$ & 0,198 & 0,143 & 0,090 & $I$ & 0,136 & 0,301 \\
\hline Specular reproduction 1 & 0,233 & $0,471^{* *}$ & 0,160 & 0,297 & 0,160 & 0,136 & $I$ & $0,431^{* *}$ \\
\hline Specular reproduction 2 & $0,454^{* *}$ & $0,367^{*}$ & 0,294 & 0,294 & 0,133 & 0,301 & $0,431^{* *}$ & $I$ \\
\hline
\end{tabular}

Figure 2 - Mediation effect of the Mental Imagery variable on the correlation between LEGO block play (independent variable) and Mathematical abilities (dependent variable); the bracketed number is the direct regression coefficient without considering the role of the mediator $\left({ }^{*} p<0.05,{ }^{* *} p<0.01\right)$

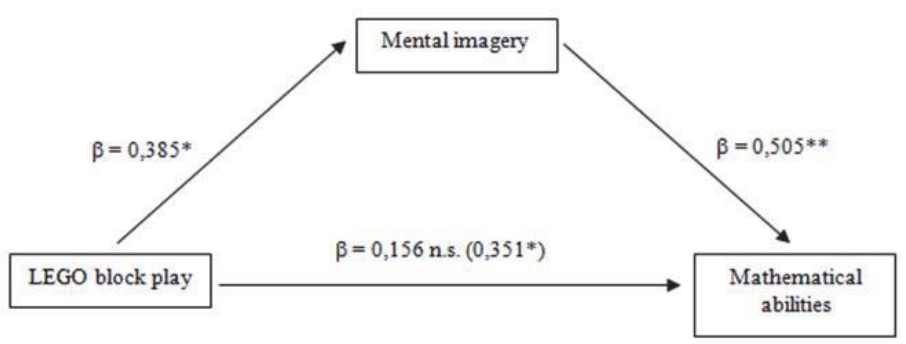


Figure 3 - Influence of the significant variables on the dependent variable (Mathematical abilities): multiple regression coefficients $(F=3.395, p=0.007, \underline{\text { s. } 0.01})$

Effect
Mental imagery
LEGO block play
Digit span memory
Visual spatial memory
Objects memory
Specular reproduction 1
Specular reproduction 2

\section{Discussion}

The aims of this study were to explore the relationship between building-block play and mathematical skills and to test mental imagery as a mechanism mediating this relationship while also taking into account gender differences. Overall, the substantial lack of gender influence in the age range considered, is in agreement with the results of longitudinal studies already available (e.g., Hanline et al., 2001; Wolfgang et al., 2003; Pirrone \& Di Nuovo, 2014), which highlights an absence of significant gender differences until the pubertal age. The better performance exhibited by males in activities involving visuo-spatial abilities is in line with previous studies (e.g., Brosnan, 1998; Caldera, 1999; Casey, Pezaris, \& Bassi, 2012). However, the lack gender influence on mental imagery appears to be in contrast with other results (e.g., Harris, 1979), which reported that males have an enhanced ability to manipulate mental images, especially when mentally rotating objects. Usually, the differences between males and females become clearer after the pubertal age. A stable acquisition of these abilities could be related to the development and improvement of formal thought, a cognitive element that is necessary for abstract reasoning (Piaget, 1945).

The significant correlations between block play, mathematics, and imagery are in agreement with the literature, as previously underlined. More specifically, the correlation of mental imagery with all the other variables confirmed its relevance as the crucial cognitive ability that binds together and synthetises the other functions during problem-solving tasks.

The results of the mediation analysis showed the importance of mental imagery. Thus, the influence of block play on mathematical skills is mainly due to the ability to manipulate mental images, therefore justifying the initial hypothesis.

Understanding a mathematical definition, proof, or concept, is strongly related to the ability to build and handle a mental object (Arnoux \& Finkel, 2009). Through the manipulation of blocks, children provide continuous reminders to the imagination, which allows them to give a concrete shape to their multitude of images and to simultaneously consolidate the principles of mathematics and geometry that are gradually acquired at school. These results support the perspective of adopting early teaching techniques that stimulate and enhance the use mental imagery through constructive play, which is assumed to be fundamental in the acquisition of math abilities. According to Golding (1998), "visualization, spatial and kinaesthetic representations, image schemata . . came to be recognised as critical to understand how mathematical concepts are meaningfully understood" (p. 138).

Further research could strengthen these results by investigating them in other age ranges and with a larger sample so that the risk of non-significance pointed out by Wolfgang et al. (2003) in pre-pubertal ages can be excluded. The frequency of LEGO use (i.e., how much time the children spent playing with blocks) and the starting age (i.e., the age at which the children started to play with blocks) was not controlled; these variables could be included in an upcoming study to enhance its predictive value. Moreover, further research could focus on the specific mechanisms by which mental imagery influences the relationship between building-block play and mathematics skills in an effort to individuate promising instruments for intervention.

\section{References}

Arnoux, P., \& Finkel A. (2009). Using mental imagery processes for teaching and research in mathematics and computer science. International Journal of Mathematical Education in Science and Technology, 41(2), 229-242.

Bishop, A. J. (1973). Use of structural apparatus and spatial ability: a possible relationship. Research in Education, 9, 43-49.

Brosnan, M. J. (1998). Spatial ability in children's play with Lego blocks. Perceptual and Motor Skills, 87, 19-28.

Brown, D., \& Wheatley, G. (1990). The role of imagery in mathematical reasoning, in Booker G., Cobb P., de Mendicuti, T. (Eds), 
Proceedings of the $14^{\text {th }}$ PME International Conference, 1, 217.

Caldera, Y. M., McDonald Culp, A., O'Brien, M., Truglio, R. T., Alvarez, M., \& Huston, A. C. (1999). Children's play preferences, construction play with blocks, and visual-spatial skills: Are they related? International Journal of Behavioral Development, 23, 855-872.

Casey, B. M., Andrews, N., Schindler, H., Kersh, J. E., Samper, A., \& Copley, J. (2008). The development of spatial skills through interventions involving block building activities. Cognition and Instruction, 26, 269-309.

Casey, B. M., Pezaris, E. E., \& Bassi, J. (2012). Adolescent boys' and girls' block constructions differ in structural balance: A blockbuilding characteristic related to math achievement. Learning and Individual Differences, 22, 25-36.

Clements, D. H., \& Sarama, J. (2007). Effects of a preschool mathematics curriculum: summative research on the building blocks project. Journal for Research in Mathematical Education, 38, 136-163.

Cornoldi, C., Friso, G., Giordano, L., Molin, A., Poli, S., Rigoni, F. \& Tressoldi, P.E. (1997). Abilità visuospaziali [Visual spatial Skills]. Trento: Erickson.

Dawe, L., \& Anderson, J. (1993). Visual imagery and metacognition in problem solving. Paper presented at the Contexts in Mathematics Education: Proceedings of the Sixteenth Annual Conference of the Mathematics Education, Research Group of Australasia, (MERGA), Brisbane.

Di Nuovo, S., Guarnera, M., Castellano, S. (2014). Mental Imagery Test, Firenze, Hogrefe.

Golding, G. A. (1998). Representational system, learning, and problem solving in mathematics. Journal of mathematical behavior, 17, 137-165.

Hampton, J. A., Passanisi A., \& Jonsson, M. (2011). The Modifier Effect and Property Mutability. Journal of Memory and Language, 64, 233-248.

Hanline, M. F., Milton, S., Phelps, P. (2001). Young children's block construction abilities: findings from 3 years of observation, Journal of Early Intervention, 24(3), 341-355.

Harris, L. J. (1979). Sex-related differences in spatial ability: a developmental psychological view, in Kopp C. B., Kilpatrick M. (edited by), Becoming female: perspectives on development, New York: Plenum Press,133-181.

Hegarty, M., \& Kozhevnikov, M. (1999). Types of visual-spatial representations and mathematical problem solving. Journal of Educational Psychology, 91, 684-689.

Hirsch, F. (1996). The block book. Washington, DC: National Association for the Education of Young Children.

Jencks, C., Smith, M., Acland, H., Bane, M. J., Cohen, D., Gintis, H., Heyns, B., \& Mitchelson, S. (1972). Inequality: A reassessment of the effects of family and schooling in America. New York: Basic Books.

Kersh, J., Casey, B. M., \& Mercer Young, J. M. (2008). Research on spatial skills and block building in girls and boys: The relationship to later mathematics learning. In B. Spodak \& O. Saracho (Eds.), Mathematics, science and technology in early childhood education: Contemporary perspectives on mathematics in early childhood education (pp. 233-253). Charlotte, NC: Information Age.

Klibanoff, R. S., Levine, S. C., Huttenlocher, J., Vasilyeva, M., \& Hedges, L. V. (2006). Preschool children's mathematical knowledge: The effect of teacher "math-talk". Developmental Psychology, 42, 59-69.

Kosslyn, S. M. (2005). Mental images and the brain. Cognitive Neuropsychology, 22, 3/4, 333-347.

Lunzer, E. A. (1955). Studies in the development of play behavior in young children between the ages of two and six. Unpublished doctoral dissertation, Birmingham University, London.

Mason, J. (1992). Doing and construing mathematics in screen-space. In B. Southwell, B.Perry, and K.Owens (Eds.), Proceedings of the Fifteenth Annual Conference of the Mathematics Education Research Group of Australasia, Nepean, Australia: University of Western Sydney, 1-17.

Nath, S., Szücs, D. (2014). Construction play and cognitive skills associated with the development of mathematical abilities in 7-year-old children. Learning and Instruction, 32, 73-80.

NCTM (National Council of Teachers of Mathematics). (2000). Principles and standards for school mathematics. Reston, VA: Author.

Oostermeijer, M., Boonen, Anton, J. H \& Jolles, J. (2014). The relation between children's constructive play activities, spatial ability, and mathematical word problem-solving performance: a mediation analysis in sixth-grade students. Frontiers in Psychology, 5, 782, Published online 2014 Jul 17. doi: 10.3389/fpsyg.2014.00782

Pace, U., Madonia, C., Passanisi, A., Iacolino, C., \& Di Maggio, R. (2015). Is Sensation Seeking Linked only to Personality traits? The role of Quality of attachment in the Development of Sensation Seeking among Italian adolescents: a longitudinal perspective. Mediterranean Journal of Social Sciences, 6(2 S1), 260-267. Doi: 10.5901/mjss.2015.v6n2s1p260.

Passanisi, A., \& Di Nuovo, S. (2015). Social and pragmatic impairments in individuals with Autism Spectrum Disorder. A lack of Theory of Mind? Life Span and Disability, 18 (1), 75-99.

Pellerone, M., Passanisi, A., \& Bellomo, M. (2015). Identity development, intelligence structure and interests: Adolescents and the decision-making process. Psychology Research and Behavior Management, 8 DOI: 10.2147/PRBM.S88631.

Pepler, D., Ross H. (1981). The effects of play on convergent and divergent problem solving. Child Development, 52(4), $1202-1210$.

Piaget, J. (1945). La formation du symbole chez l'enfant: Imitation, jeu et rêve, image et representation [Symbol formation in childhood: Imitation, play and dream, image and representation]. Paris, France: Delachaux et Niestlé.

Picket, L. (1998). Literacy learning during block play. Journal of Research in Childhood Education, 12, 225-230.

Pirrone, C., Di Nuovo, S. (2014). Can playing and imagining aid in Learning Mathematics? An experimental study of the relationships among Building-Block Play, Mental Imagery, and Arithmetic Skills. Applied Psychology Bulletin, 62, 30-40. 
Presmeg, N. C. (1986). Visualization in high school mathematics. For the Learning of Mathematics, 6(3), 42-46.

Presmeg, N. C. (1992). Prototypes, metaphors, metonymies and imaginative rationality. High School Mathematics. Educational Studies in Mathematics, 23,595-610.

Reifel, S. (1984). Block construction: Children's developmental landmarks in representation of space. Young Children, 40, 61-67.

Sarama, J., \& Clements, D. H. (2009). Early childhood mathematics education research: Learning trajectories for young children. New York, NY: Routledge.

Schimmenti, A., Di Carlo, G., Passanisi, A., Caretti, V. (2015). Abuse in childhood and psychopathic traits in a sample of violent offenders. Psychological Trauma: Theory, Research, Practice, and Policy, 7(4), 340-347 DOI: 10.1037/tra0000023.

Shaklee, H., O'Hara, P., \& Demarest, D. (2008). Early math skills: Building blocks for the future. Research Brief, University of Idaho Extension.

Soresi, S., Corcione D., Gruppo Emmepiù (1992). Prove oggettive di matematica per la scuola elementare [Objective tests of mathematics for primary school], O.S., Firenze.

Stroud, J. E. (1995). Block play: Building a foundation for literacy. Early Childhood Education Journal, 23, 9-13.

Tracy, M. D. (1987). Toys, spatial ability, and science and mathematics achievement: Are they related? Sex Roles, 17, 115-138.

Varol, F., \& Farran, D. (2006). Early mathematical growth: how to support young children's mathematical development. Early Childhood Education Journal, 33, 381-387.

Verdine, B. N., Golinkoff, R. M., Hirsh-Pasek, K., Newcombe, N. S., Filipowicz, A. T., and Chang A. (2014). Deconstructing Building Blocks: Preschoolers' Spatial Assembly Performance Relates to Early Mathematical Skills. Child Development, 85(3), 10621076.

Vygotsky, L. S. (1976). Play and its role in the mental development of the child. In J. S. Bruner, A. Jolly, \& K. Sylva (Eds.), Play: Its role in development and evolution (pp. 536-552). New York, NY: Basic Books.

Jencks, S. M. \& Peck, D. M. (1972). Mental imagery in mathematics, The Arithmetic Teacher, 19(8), 642-644.

Wolfgang, C. H., Stannard, L. L., Jones, I. (2003). Advanced constructional play with LEGOs among preschoolers as a predictor of later school achievement in mathematics, Early Child Development and Care, 173(5), 467-475.

Zacks, J. M., \& Tversky, B. (2003). Structuring information interfaces for procedural learning. Journal of Experimental Psychology: Applied, 9, 88-100. 